\title{
Recent progress in microRNA study: Benefits from technique advance
}

\author{
YU Jia ${ }^{*} \&$ WANG Fang \\ Department of Biochemistry and Molecular Biology, National Laboratory of Medical Molecular Biology, Peking Union Medical College \& \\ Chinese Academy of Medical Sciences, Beijing 100005, China
}

Received June 7, 2012; accepted June 23, 2012

Citation: Yu J, Wang F. Recent progress in microRNA study: Benefits from technique advance. Sci China Life Sci, 2012, 55: 649-650, doi: $10.1007 / \mathrm{s} 11427-012-4342-7$

Over the last decade, sequencing of different genomes revealed that an increase in organismal complexity is not merely explained by a dramatic increase in the number of protein-coding genes. However, the gradual increase in protein diversity contributes a lot to the complexity of higher organisms [1]. It is now widely accepted that non-coding RNAs (ncRNAs), especially microRNAs (miRNAs) largely define eukaryotic cell functions and the impacts of a variety of gene regulation [2].

As the first step, the identification and functional annotation of miRNAs are extremely important for elucidating miRNA biology. From then on, microchip [3], microarray [4,5] and RNA-Seq technology [6] have been widely used in miRNA gene identification, expression profile establishment and function investigation. Recently, the combination of some computational approach to experimental techniques makes miRNA research more convenient [7-9]. For example, numerous ncRNA databases, such as RNAdb [10], NONCODE [11], deepBase [12], miRBase [13], and Rfam [14], facilitate the usage of transcript information by miRNA researchers. A number of ncRNA gene prediction algorithms were also developed for the large-scale identification of new miRNAs [15-17]. The final purpose of identifying ncRNA genes is to reveal their function. ncRNAs often serve their roles by interacting with other molecules, therefore a series of algorithms were established to find target molecules, especially for miRNAs, such as miRanda [18],

*Corresponding author (email: j-yu@ibms.pumc.edu.cn)
TargetScan [19], PicTar [20], and RNAhybrid [21].

Recently, the miRNA research also benefits from large progress in synthetic biology, e.g., a sensor for miRNA, which carried miRNA target sequences downstream to the 3'-untranslated region of Gaussia princeps luciferase (Gluc) gene, was developed to monitor in vivo miRNA activity in cell supernatants and peripheral blood [22].

Based on the above technique advances, some miRNAs and their functions in different species, including rats [23], tomatoes [24] and viruses [4,25], and in different human diseases, including acute myeloid leukemia [26], uveal melanoma [6], atrial fibrillation [27] and neurodegenerative diseases [5], have been well studied. These disclosed miRNAs may help promote the diagnosis of specific disease, and may be useful in developing therapies targeting miRNAs.

1 Martinez N J, Walhout A J. The interplay between transcription factors and microRNAs in genome-scale regulatory networks. Bioessays, 2009, 31: 435-445

2 Zhang Y. Progress, challenges and new concepts in microRNAs. Sci China Life Sci, 2011, 54: 1096

3 Yang C, Wei W. The miRNA expression profile of the uveal melanoma. Sci China Life Sci, 2011, 54: 351-358

4 Luo J, Teng M, Fan J, et al. Marek's disease virus-encoded microRNAs: genomics, expression and function. Sci China Life Sci, 2010, 53: 1174-1180

5 Feng W, Feng Y. MicroRNAs in neural cell development and brain diseases. Sci China Life Sci, 2011, 54: 1103-1112

6 Li S, Yu B, Wang Y, et al. Identification and functional annotation of novel microRNAs in the proximal sciatic nerve after sciatic nerve 
transection. Sci China Life Sci, 2011, 54: 806-812

7 Zheng L, Qu L. Computational RNomics: structure identification and functional prediction of non-coding RNAs in silico. Sci China Life Sci, 2010, 53: 548-562

8 Chen G, Wang C, Shi T. Overview of available methods for diverse RNA-Seq data analyses. Sci China Life Sci, 2011, 54: 1121-1128

9 Chen G, Yin K, Wang C, et al. De novo transcriptome assembly of RNA-Seq reads with different strategies. Sci China Life Sci, 2011, 54: 1129-1133

10 Pang K C, Stephen S, Engstrom P G, et al. RNAdb - a comprehensive mammalian noncoding RNA database. Nucleic Acids Res, 2005, 33: D125-130

11 Liu C, Bai B, Skogerbo G, et al. NONCODE: An integrated knowledge database of non-coding RNAs. Nucleic Acids Res, 2005, 33: D112-115

12 Yang J, Shao P, Zhou H, et al. deepBase: A database for deeply annotating and mining deep sequencing data. Nucleic Acids Res, 2010, 38: D123-130

13 Griffiths-Jones S, Saini H K, van Dongen S, et al. miRBase: Tools for microRNA genomics. Nucleic Acids Res, 2008, 36: D154-158

14 Gardner P P, Daub J, Tate J G, et al. Rfam: Updates to the RNA families database. Nucleic Acids Res, 2009, 37: D136-140

15 Hofacker I L. Vienna RNA secondary structure server. Nucleic Acids Res, 2003, 31: 3429-3431

16 Washietl S, Hofacker I L, Stadler P F. Fast and reliable prediction of noncoding RNAs. Proc Natl Acad Sci USA, 2005, 102: 2454-2459

17 Faulkner G J, Kimura Y, Daub C O, et al. The regulated retrotrans- poson transcriptome of mammalian cells. Nat Genet, 2009, 41: 563-571

18 Enright A J, John B, Gaul U, et al. microRNA targets in Drosophila. Genome Biol, 2003, 5: R1

19 Lewis B P, Burge C B, Bartel D P. Conserved seed pairing, often flanked by adenosines, indicates that thousands of human genes are microRNA targets. Cell, 2005, 120: 15-20

20 Krek A, Grun D, Poy M N, et al. Combinatorial microRNA target predictions. Nat Genet, 2005, 37: 495-500

21 Maragkakis M, Reczko M, Simossis V A, et al. DIANA-microT web server: Elucidating microRNA functions through target prediction. Nucleic Acids Res, 2009, 37: W273-276

22 Wang G, Dong X, Hu J, et al. Long-term ex vivo monitoring of in vivo microRNA activity in liver using a secreted luciferase sensor. Sci China Life Sci, 2011, 54: 418-425

23 Zhang Y, Dong D, Yang B. Atrial remodeling in atrial fibrillation and association between microRNA network and atrial fibrillation. Sci China Life Sci, 2011, 54: 1097-1102

24 Zuo J, Wang Y, Liu H, et al. MicroRNAs in tomato plants. Sci China Life Sci, 2011, 54: 599-605

25 Wu J, Wang C, Du Z, et al. Identification of Pns12 as the second silencing suppressor of Rice gall dwarf virus. Sci China Life Sci, 2011, 54: 201-208

26 Chen H, Chen Q, Fang M, et al. microRNA-181b targets MLK2 in HL-60 cells. Sci China Life Sci, 2010, 53: 101-106

27 Feng Y, Yu X. Cardinal roles of miRNA in cardiac development and disease. Sci China Life Sci, 2011, 54: 1113-1120

Open Access This article is distributed under the terms of the Creative Commons Attribution License which permits any use, distribution, and reproduction in any medium, provided the original author(s) and source are credited. 